\title{
Do core stability exercises improve upper limb function in chronic stroke patients?
}

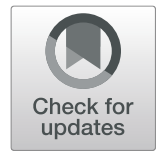

H. El-Nashar ${ }^{1}$, A. ElWishy ${ }^{1}$, H. Helmy ${ }^{2 *}$ and R. El-Rwainy ${ }^{1}$

\begin{abstract}
Background: Upper limb paresis is a common problem in patients with stroke.

Objectives: To determine the effect of core stability exercises on upper limb function and trunk balance in hemiparetic patients.

Subjects: Thirty patients with hemiparesis, with age between 45 and 60 years, and with illness duration of more than 6 months. They were assigned into two equal groups, the control group, Group A: with 15 patients who received only conventional physical therapy program; the study group, Group B: with 15 patients who received conventional physical therapy program and additional core muscle training. Patients received 18 sessions for 6 weeks, three sessions/week.

Methods: The upper limb function was assessed using Wolf motor function test with subscales (function ability scale, time, and grip strength), the range of motion of shoulder flexion and abduction was measured by using goniometer, trunk balance was assessed using the trunk impairment scale with subscales (static sitting balance, dynamic sitting balance, and coordination). All measurement outcomes were assessed before and after applying the treatment program.
\end{abstract}

Results: There was no statistical significant difference between two groups in pretreatment assessment using wolf motor function test, trunk impairment scale, and shoulder range of motion. In post treatment assessment, there was no statistical significant difference between group A and group B in all the outcome measures, except for trunk impairment subscale (dynamic sitting balance); the statistical significant difference was in favor of group B.

Conclusion: Core muscle training is similar to conventional physical therapy program in improving upper limb function in hemiparetic patients, and has beneficial effect on improving trunk balance.

Keywords: Hemiparesis, Upper limb function, Core muscle training

\section{Introduction}

Stroke is a common nervous system disorder. Stroke survivors can suffer some neurological impairments such as hemiparesis, communication disorders, cognitive deficits, or disorders in visuospatial perception [1].

Stroke is subdivided into three phases, the initial phase or acute stroke that starts immediately following cerebrovascular accident and continues for 2 weeks. The next phase is subacute stroke that continues for many months up to 6 months following stroke. The last phase is the chronic stroke that continues from months to years following stroke and the patient may complete his life with this phase $[2,3]$.

\footnotetext{
* Correspondence: drhananelgendy76@gmail.com

${ }^{2}$ Department of Neurology, Faculty of medicine, Cairo University, Giza, Egypt

Full list of author information is available at the end of the article
}

Mobility of the upper limbs is vital for daily activities, functional activities, and quality of life [4]; upper limb paresis following stroke leads to limitations of daily activities, functional activities, and social roles [5].

The core muscles have a great function in stability and mobility of body parts in maintaining posture and assisting the mobility of upper and lower limbs, against gravity, so facilitating function of arms and legs [6, 7].

Many patients with stroke suffer from insufficient trunk control, affecting their functional ability in many activities, example: turning in bed, sitting up/lying down, rise from sitting to standing, standing, and walking. Impaired anticipatory activity of the superficial lateral trunk muscles (latissimus dorsi, rectus abdominis, and external oblique) on the paretic side has been found to influence their ability to perform activities of daily living [8]. 
Stroke patients demonstrated altered trunk position sense; this may be caused by insufficient co activation of abdominal and back muscles. In sitting position, weakness of abdominal muscles may cause the line of gravity to be placed relatively posterior to the center of gravity, so increasing the liability to fall backwards. Stroke patients may compensate by sitting with excessive flexed, thoracic spine to avoid falling backward during sitting [9].

Core stability has a high established reliability concerning improving the trunk muscle performance [10]; as core muscles supporting the lumbo-pelvic-hip complex, researchers have reported that core stability training could improve not only trunk function but also balance and mobility [11].

In rehabilitation of stroke patients, postural control is necessary for smooth functional activity; core stability plays a major role in maximizing function and minimizing weight bearing at the joints while doing various activities like walking, running, and throwing [12].

Exercises for core-stability serve as treatment for simultaneously activating the abdominal and multifidus muscle in order to stabilize the body and head during the beginning of limb movement and during the course of these movements [13]. In this study, we aimed to determine the effect of core stability exercises on upper limb function and trunk balance in hemiparetic patients.

To our knowledge, there is lack of research of the effect of core muscle training on upper limb function. On the other hand, the effect of core muscle training exercises was studied on balance and mobility of stroke patients [14-16]. Also, core stability exercises effect was investigated on balance and trunk control of stroke patients [17]. Another study examined the effect of core stabilization exercises on balance and gait of stroke patients $[18,19]$. So, we meant that the lack of research concerning the effect of core muscle training on limb function was in the relation between core muscle training and upper limb.

This study investigates the effect of core muscle training on chronic stroke patients while other study investigated the effect of core stability exercises on subacute stroke patients [17, 20]. Also, another study investigated the effect of trunk stability exercises on early or acute stroke patients [21]. But no study investigated the effect of core stabilization exercises on chronic stroke patients as in this study.

Upper limb impairment in stroke patients is more than lower limb involvement. Despite the degree of weakness between the upper and the lower limbs is similar but it was found that the lower limb is stronger than the upper limb so the proper modalities and interventions used for upper limb rehabilitation should be taken into consideration [22].
A study by Nilufer studied a correlation between upper limb movement and trunk control in patients with multiple sclerosis and found that there was high correlation between upper limb movement and trunk control as with improving trunk control and stability, the upper limb movement was also improved [23].

The hypothesis of this study was that the core stability exercises had an effect on the upper limb function and trunk balance in chronic stroke patients.

\section{Patients and methods}

The present study was held in the outpatient clinic, Faculty of Physical Therapy, Cairo University between May 2017 and March 2018. It is a randomized controlled trial; it was approved by the ethical committee of the faculty of physical therapy, Cairo University, Egypt (Approval Number: P.T.REC/012/001594).

Thirty patients had experienced their first stroke, whether ischemic or hemorrhagic. The stroke diagnosis was based on the World Health Organization guidelines [24] and was confirmed by clinical examination and magnetic resonance imaging. All patients were subjected to a full clinical neurological assessment. Study participants were randomly allocated to either control group (group A) or study group (group B) by means of a random computer-generated list specific to each center. The randomization was managed by an external person uninvolved in the treatment. The method of allocation was concealed in sequentially numbered, sealed envelopes.

All patients followed the conventional therapy program for stroke patients provided for a period, consisting of $30 \mathrm{~min}$ of treatment per session, three times per week for 6 weeks (18sessions).

Inclusion criteria: Included in this study are patients with spasticity on the Modified Ashworth Scale (MAS) between grade (+1 and 2) [25], the duration of illness was more than 6 months, and age ranged between 45 and 60 years old. The affected upper limb had a moderate motor impairment. The scores of upper limb motor performance ranged from (19-40) according to FuglMeyer scale for the section of upper limb and hand [26].

Exclusion criteria included patients with balance disturbance due to neurological disorders other than stroke (example: Parkinson's disease, inner ear, vestibular, or cerebellar dysfunctions), with musculoskeletal disorders such frozen shoulder or degenerative diseases affecting the posture and motor performance as ankylosing spondylitis, with communication problems, and those with a history of previous stroke or other neurologic diseases or disorders. Patients with pain, limited motion, or weakness in the non-paretic lower extremity that affect performance of daily activities, those with uncontrolled hypertension or symptomatic cardiac failure or unstable angina, and patients with respiratory disorders or 
conditions that may influence the posture of the skeletal system of the back (example: asthma).

The patients with pain in non-paretic lower limb were excluded from our study because some exercises like bridging and quadruped involve weight bearing on both lower limbs which hampers the performance of the exercises.

The functional ability of the upper limb was assessed by wolf motor function test (WMFT) which is valid and commonly used assessment tool of upper extremity functional ability [27].

For the stroke population, it uses two strength measurements and a series of 15 functional tasks that progress from simple movements in proximal joint areas to complex movements in distal joint areas. Each of the 15 tasks is timed to completion, up to a maximum of $120 \mathrm{~s}$. Functional ability sub-scores represent the quality of the movement during the performance of these functional tasks.

Trunk function was evaluated with the trunk impairment scale (TIS). This consists of a total of 17 items: three regarding static sitting balance, ten regarding dynamic sitting balance, and four about coordination. Patients receive a total between 0 and 23 points [28].

Range of motion of shoulder flexion and abduction was recorded in degrees with the utilization of a standard goniometer. The reliability of a goniometer is shown with an intra-class correlation coefficient (ICC) of 0.95 by Khamwong and colleagues [29].

The patients in group A received stretching exercises for shoulder girdle muscles such as pectoralis major muscle; the patient put both hands behind the head and the therapist was behind him attaching the elbow with pulling the arms backward, maintaining the action for $30 \mathrm{~s}$ [30]; strengthening exercises for shoulder muscles including active resisted shoulder abduction-the patient was asked to do active resisted shoulder abduction within the available range of motion and within the limit of pain; active resisted shoulder external rotation-the patient was asked to do active resisted shoulder external rotation within the available range and against resistance keeping the trunk aligned; upper trapezius muscle strengthening-the patient performed the shoulder shrugging within the available range against suitable resistance while keeping the trunk well aligned. Serratus anterior muscle strengthening-the patient was asked to push forward by his upper limb against the applied resistance and was asked to keep proper trunk alignment [31] and trunk control exercises including (active trunk flexion), the patient was sitting, and then was asked to do active trunk lateral flexion while the therapist guides the motion. Active trunk rotation-the patient was asked to do active trunk rotation while keeping the trunk in the extended position [32]. Each exercise was repeated for ten times in two sets, giving rest in between for $10 \mathrm{~s}$ after each set. The duration of the session was 30-min duration with rest in between.

The patients in group B received treatment as in group A in addition to core stability exercises aiming for increasing trunk stability and increasing activation of abdominal and back muscle. The duration of the session was $30 \mathrm{~min}$ with 10-min rest in between fora period of 6 weeks [33]. The core stabilization exercises consisted of two subparts: First, the bed exercises that consist of bridge exercise-patient lies supine with hips and knees bent $90^{\circ}$ with feet flat on floor and palms are down at sides, draw in the abdominal muscles and then slowly raising buttocks off the table by using gluteus and hamstrings [34]; bridge exercise with legs crossed-patient lies supine with one hip and knee bent to $90^{\circ}$ with feet flat on floor and another leg rested on the opposite knee and palm-down at sides then draw in abdominal muscles then slowly raising his buttocks off the table by using his gluteus and hamstrings [34]; bridge exercise with one leg-patient lies supine with his knees bent and his feet flat on the floor. The patient lifts pelvis forming a bridge. Then lifting right leg off the floor and extends it [34]. Curl-ups with straight reaching-patient lies supine with his knees bent and his feet flat on the floor. "Crunch" or curl his stomach to lift the shoulders just off the floor [34]. Curl-ups with diagonal reaching-patient lies supine with his knees bent and his feet flat on the floor. The patient crunches or curls the stomach to lift the shoulders off the floor and twist, reaching his right elbow towards his left leg. Then returning to the floor and repeat twisting in the opposite direction lifting his shoulders just off the floor [35]. Quadruped exercisepatient balances on the floor on his hands and knees. The patient's back should be flat and hips parallel to the floor. Then the patient is asked to do cat and camel motion (spine flexion and extension) [34]. Bird dog exercise-patient balances on the floor on his hands and knees. The patient's back should be flat and hips parallel to the floor. The patient raises his right arm out in front of him and raises his left leg out behind him, keeping it straight [35]. At each exercise, there is hold for 3-5 s and repetition from 10 to 20 times.

The second subpart is the ball exercises that consisted of bridge exercise-the patient lies supine on the floor with knees straight, feet resting on physio-ball, arms at sides; draw in abdominal muscles; slowly lift the buttocks off floor and segmental rotation-the patient lies supine on the floor with hips and knees bent to $90^{\circ}$ over a physio-ball; draw in abdominal muscles; slowly and with control, rotate knees to one side keeping hips in contact with the floor; engage abdominal obliques to pull knees back to center and repeat on the opposite side [34]. At each exercise, there is hold for 3-5 s and repetition from 10 to 20 times. 
All measurement outcomes were assessed pre- and post-testing phases of the study; after applying the treatment program for the patients for successive 6 weeks. The posttreatment assessment was done at the end of the last treatment session.

\section{Statistical analysis}

The collected data were coded, tabulated, and statistically analyzed using IBM SPSS Statistics (Statistical Package for Social Sciences) software version 22.0, IBM Corp., Chicago, USA, 2013. Descriptive statistical analysis was performed for all pre- and posttreatment variables and all data are expressed as mean and standard deviation. The box and whiskers plots of the tested variable were done to detect outliers. Normality test of data using Shapiro-Wilk test was used, that reflect the data was normally distributed for all dependent variables. Accordingly, $2 \times 2$ mixed design MANOVA was used to compare the tested variables of interest at different tested groups and measuring periods. With the initial alpha level set at 0.05 . Prior to final analysis, data were screened for normality assumption, homogeneity of variance, and presence of extreme scores. This exploration was done as a pre-requisite for parametric calculations of the analysis of difference. Descriptive analysis using histograms with the normal distribution curve showed that ROM of shoulder abduction and flexion, WFMT (function ability score and time, grip strength), and Trunk impairment (static and dynamic sitting balance score and coordination) score were normally distributed and not violate the parametric assumption for the measured dependent variable.

\section{Results}

A total of 15 control group and 15 study group participants were included in the analysis. Figure 1 shows the flow diagram for the study. The current test involved two independent variables. The first one was the (tested group); between subject factor which had two levels (group A receiving conventional physical therapy program and group B receiving conventional physical therapy program in addition to core muscle training). The second one was the (measuring periods); within subject factor which had two levels (pre, post). In addition, this test involved tested dependent variables (ROM of shoulder abduction and flexion, WFMT (function ability score and time, grip strength), trunk impairment scale (static and dynamic sitting balance score and coordination score). The age of the patients ranged from 45 to 60 years with a mean age of56.9 \pm 7.24 years for group A and $59.86 \pm 8.14$ for group B. General characteristics of the patient group are shown in Table 1 .

Results showed that in the Wolf Motor Function Test subscales (function ability score, time, grip strength), there were no statistical significant difference between the control and the study group Figs. 2 and 3.

Concerning shoulder abduction (ROM), the $p$ value between group A and group B pretest was 0.832 and posttest was 0.142 . Concerning shoulder flexion, the $p$ value between group A and group B pretest was 0.221 and posttest was 0.052 Fig. 4 .

In the Trunk Impairment scale, there was statistical significant difference in the dynamic sitting balance subscale scale in favor to the study group B; on the other hand, there was no statistical significant difference in the other subscales of the TIS (static sitting balance and coordination) between both groups Fig. 5 .

\section{Discussion}

In this study, it was found that the core muscle training had no additional effect on improving upper limb function when comparing it with conventional physical therapy program; on the other hand, it had a significant effect on improving trunk balance in chronic stroke patients. This indicates the importance of core muscle training on improving trunk balance in chronic stroke patients. One of the limitations of this study was the duration of treatment which was 6 weeks.

Concerning the primary outcome measure Wolf Motor Function Test, there was no statistical significant difference in WMFT in the function ability and time of task performance in upper extremity between both groups.

These findings were supported by Sun and colleagues' findings [36] who stated that modified Barthel index and berg balance scale scores were significantly improved in both the study and control groups with comparison with the pre-treatment results. This proves that both core stability exercises and conventional exercises can improve the abilities of stroke patients mainly the daily activities and their ability to control body balance $[13,11]$.

These results came in consistent with $\mathrm{Yu}$ and colleagues' findings [13] who reported that there was no statistical significant difference in muscle activity of lower trunk before and after performing core stabilityenhancing exercises.

The insignificant improvement in the upper limb function may be related to the duration of illness of patients as they were chronic stroke patients (more than six months), as the duration of illness is one of the main factors that affect the patient's neural plasticity and motor recovery [37].

Longer duration of illness may lead to maladaptive strategies becoming part of the daily movement repertoire. Compensatory movement strategies may be very difficult to unlearn, frustrating efforts to improve movement for both patient and therapist [38]. 


\section{Consort Flow Diagram}

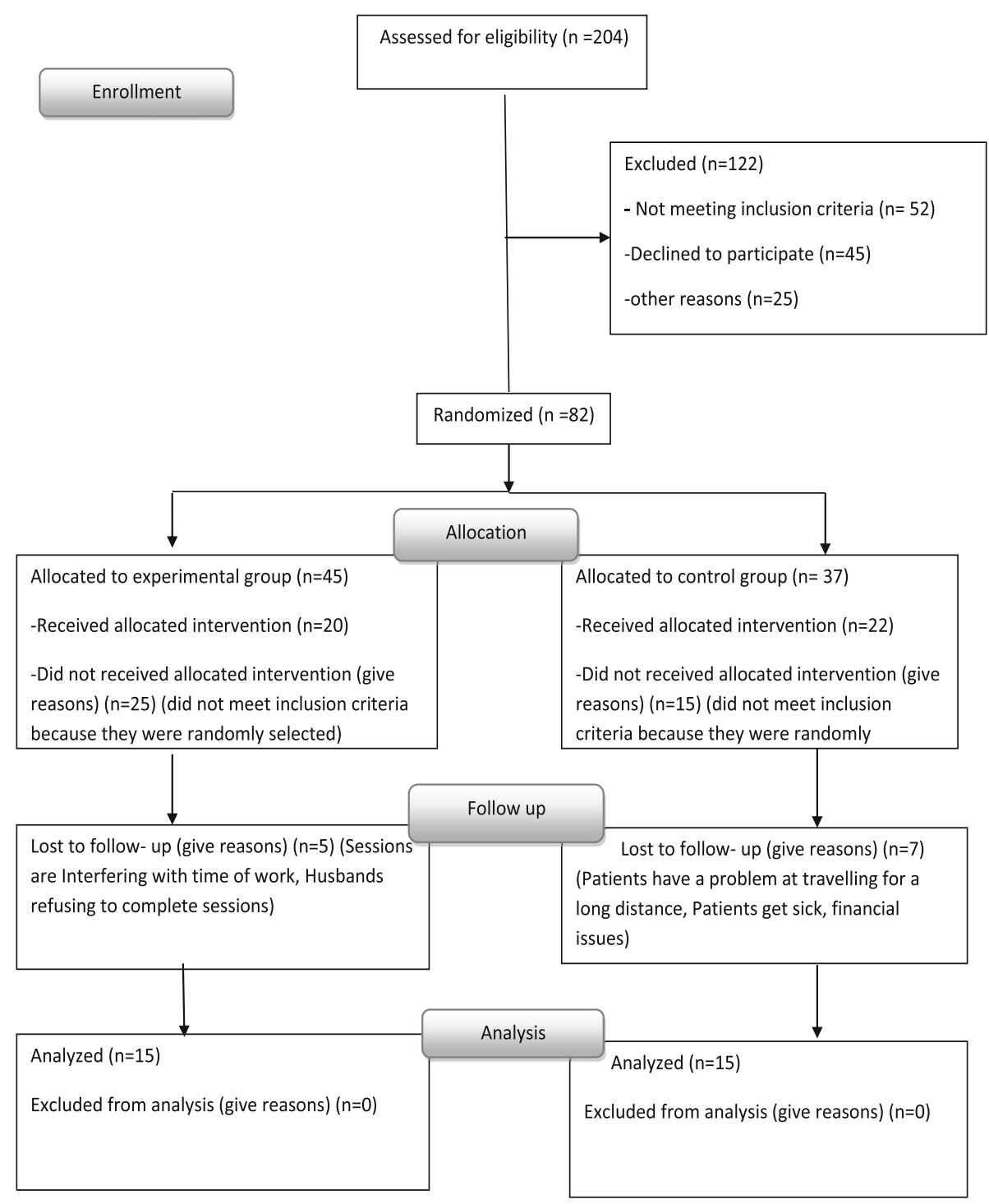

Figure (1): Study Consort

Fig. 1 Study consort

Table 1 Physical characteristics of patients in both groups

\begin{tabular}{|c|c|c|c|c|c|}
\hline \multirow[t]{2}{*}{ Items } & \multirow{2}{*}{$\begin{array}{l}\text { Group A } \\
\text { Mean } \pm \text { SD }\end{array}$} & \multirow{2}{*}{$\begin{array}{l}\text { Group B } \\
\text { Mean } \pm \text { SD }\end{array}$} & \multicolumn{2}{|c|}{ Comparison } & \multirow[t]{2}{*}{ S } \\
\hline & & & $t$ value & $P$ value & \\
\hline Age (years) & $56.9 \pm 7.24$ & $59.86 \pm 8.14$ & 0.931 & 0.362 & NS \\
\hline Body mass (kg) & $77.2 \pm 5.43$ & $81.33 \pm 9.28$ & 1.265 & 0.218 & NS \\
\hline Height (cm) & $168.4 \pm 7.66$ & $167.2 \pm 9.26$ & -0.339 & 0.738 & NS \\
\hline Duration of illness (years) & $3.15 \pm 1.59$ & $2.66 \pm 1.34$ & -0.816 & 0.423 & NS \\
\hline
\end{tabular}

SD standard deviation, $P$ probability, $S$ significance, NS non-significant 


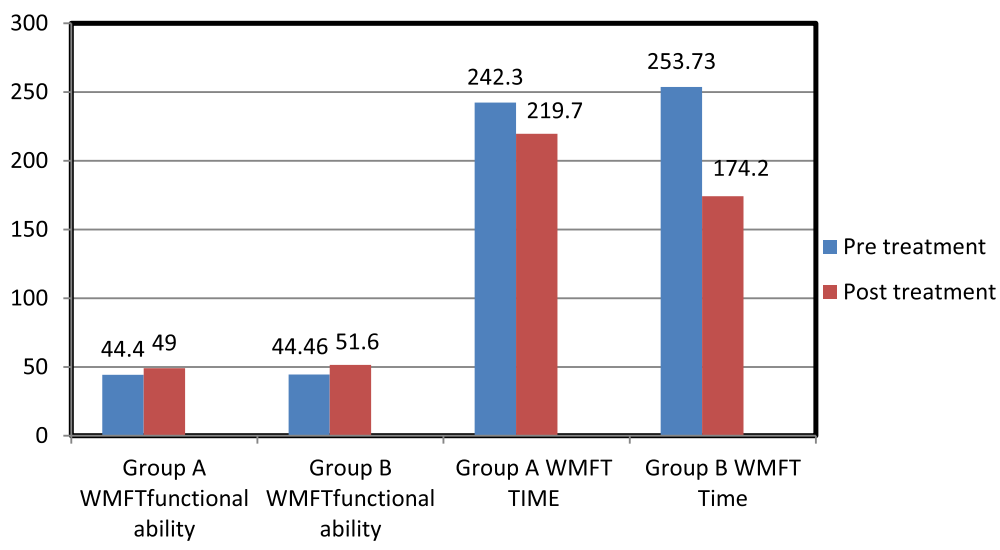

Fig. 2 Mean values of WMFT function ability and time scores pre- and posttests in both groups

Another study by Esther stated that there was no significant effect of application of core stability training on balance and gait in multiple sclerosis patients [39].

Another explanation for the insignificant difference between both group A and group B in our study may be attributed to the insufficient duration of exercise. Six weeks of core stability exercises may not be enough to produce significant improvement in muscle strength that appears in comparison between groups [40] and not enough to produce change in upper limb function, as the rate of gain from exercises may not be obvious.

Our study results come in agreement with the results of Jamison and colleagues [41] who concluded that the length of core program of 8 weeks was not enough to elicit performance enhancement. Also, this study results were confirmed by the results of Lust and colleagues [42] who revealed that there were no significant differences between both groups following six weeks of core stability training.

Another possible explanation to the insignificant improvement in the upper limb function may be due to impaired reaching caused by abnormal elbow flexor synergy patterns involving excessive coactivation between elbow flexors and elbow extensors with activation of shoulder abductors, so the resultant joint torque involved coupling of shoulder abduction with elbow flexion, [43] or spasticity of the biceps so affecting or impairing upper extremity function [44, 45]. In this study, as the patient were of moderate spasticity, so this explained the poor recovery of the upper limb function, so training may not have addressed the right motor deficits.

On the other hand, our insignificant difference concerning WMFT was opposed by the findings of Miyake and colleagues [46] who reported that core stabilization exercises enhance trunk balance to improve upper extremity function as improving proximal stability improve distal mobility. In addition, the results of Woodbury and colleagues [47] proved that stable trunk provides a reference point for the extremities to move freely.

The TIS as secondary outcome measure showed a statistical significant change in dynamic sitting balance in

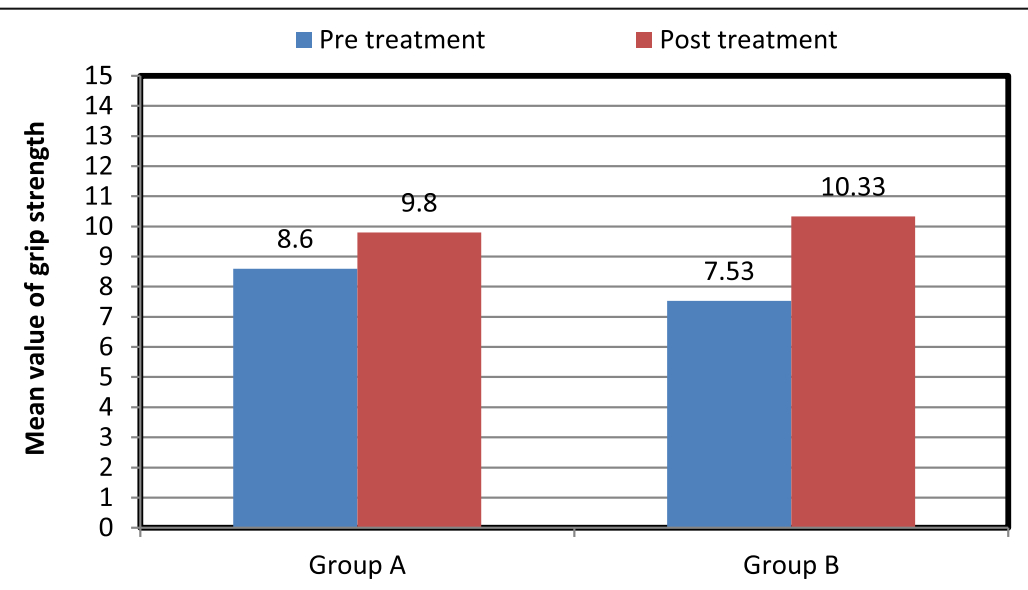

Fig. 3 Mean values of grip strength pre- and posttests in both groups 


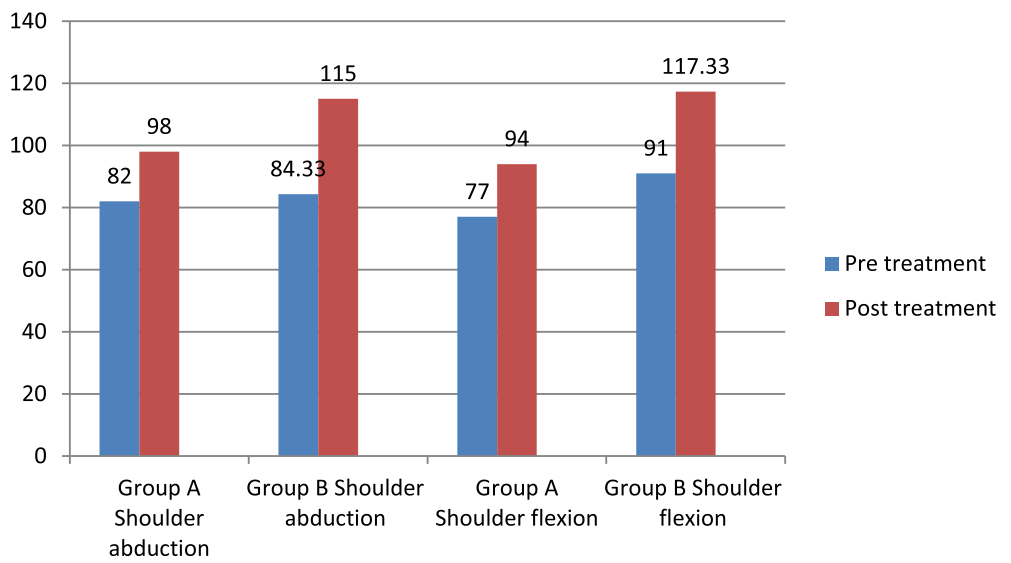

Fig. 4 Mean values of ROM of shoulder abduction and flexion pre- and posttests in both groups

favor to the study group. Static sitting balance and coordination showed no significant difference between both groups. The static sitting balance subscale has been pointed out to readily show a ceiling effect [48].

Verheyden and colleagues [49] reported that the subscales of the trunk impairment scale are hierarchical (as stated that static sitting balance appeared easier to improve than dynamic sitting balance, which in turn was easier to improve than coordination). Such a hierarchy may explain why the study did not demonstrate beneficial effects for the study group compared to the control group for coordination.

Saeyset and colleagues [50] reported that $16 \mathrm{~h}$ of additional trunk exercises improved trunk function, dynamic sitting balance, and trunk coordination. As improving trunk function will augment postural control during standing balance and mobility. This indicates the importance of trunk exercises in the rehabilitation of stroke patients.
These results were consistent with the results of Cabanas-Valdes and colleagues [11] who found a statistical significant difference in all the outcome measures which concluded that core stability exercise training along with conventional therapy improved standing balance, gait, and activities of daily living in sub-acute post stroke patients.

Verheyden and colleagues [51] also stated that core stability exercises were beneficial for improving balance and selective trunk movement in cerebrovascular accident patients.

We could not explain that the improvement was due to spasticity or weakness and both of them were not measured. Our main outcomes were WMFT as primary outcome measure, ROM and TIS as secondary outcome measure, so we could not decide whether improvement was due to spasticity or weakness. Also, in inclusion criteria, patients were selected with spasticity on the Modified Ashworth Scale (MAS) between grade (+1 and 2),

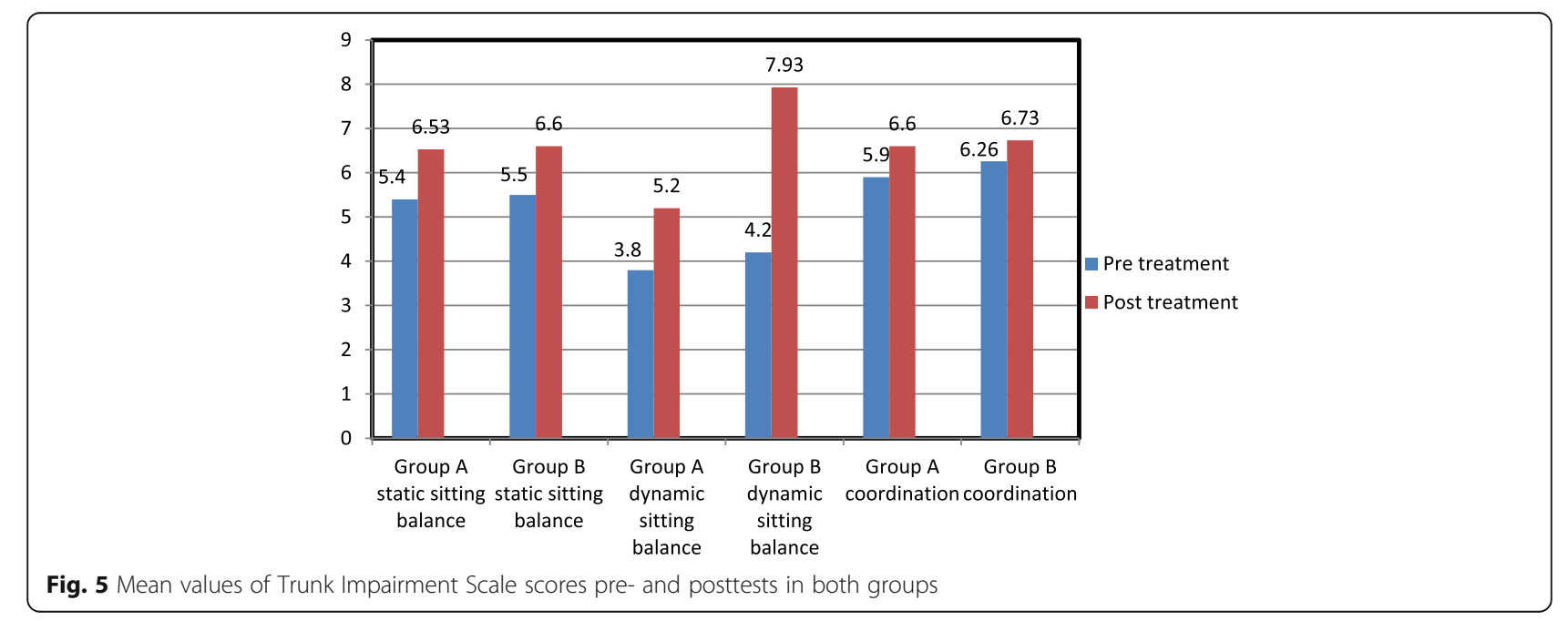


so it is mild spasticity that has no effect so improvement may be due to improving weakness.

Concerning the independent variable range of motion of shoulder abduction and flexion, there was no statistical significant differences in the range of motion of shoulder abduction and flexion between both groups.

Our findings of the insignificant difference of the shoulder range of motion was supported by the findings reported by Wee and colleagues [52] who concluded that trunk control exercise has a moderate effect on reduction of upper extremity impairment in chronic stroke patients, in terms of Fugl-Meyer assessment for upper extremity score. There is insufficient evidence to support that trunk exercises improve upper extremity function and reaching trajectory smoothness and straightness in chronic stroke patients.

On the other hand, our findings of insignificant difference in shoulder range of motion were opposed by the significant difference reported by Mahiba and colleagues [53] who concluded that the addition of core muscle exercises along with conventional set of exercises in hemiplegic patients can improve the reaching activities of the upper extremities. In this study, the result showed statistical significant improvement in reaching activity after performing core muscle exercise.

Our results were not matched with the study of Mahiba and colleagues as our primary outcome measure was WMFT while the primary outcome measure of Mahiba and colleagues was reaching, so our results were not matched with results of Mahiba and colleagues.

\section{Conclusion}

It was concluded that core stability exercises for 6 weeks add no beneficial effect in comparison with conventional physical therapy program in improving upper limb function in chronic stroke patients and so it is highly recommended that the duration of the treatment to be more than 6 weeks, but there was beneficial effect on improving trunk balance.

\section{Abbreviations \\ ADL: Activity of daily living; CMS: Core muscle strength; CNS: Central nervous system; CT: Computed tomography; CVA: Cerebrovascular accident; CVS: Cerebrovascular stroke; FMA-UE: Fugl-Meyer Assessment Upper Extremity; ICC: Intraclass correlation coefficient; MAS: Modified Ashworth Scale; MRI: Magnetic resonance imaging; QOL: Quality of life; ROM: Range of motion; TIS: Trunk Impairment Scale; UE: Upper extremity; WMFT: Wolf Motor Function Test}

\section{Acknowledgements}

The authors acknowledge subjects for their participation and cooperation in this study.

\section{Funding}

This research received no specific grant from any funding agency in the public, commercial, or not-for-profit sectors. Personnel funding by the authors themselves.

\section{Availability of data and materials}

The datasets generated and/or analyzed during the current study are not publicly available due to current Cairo University regulations and Egyptian legislation but are available from the corresponding author on reasonable request and after institutional approval.

\section{Authors' contributions}

HAE wrote the paper, participated in the design, and collected the materials and data. AAE performed the statistical analysis, revised the paper, and participated in design of the paper and the sequence alignment. HHM participated in the design of the paper, sequence alignment, and revised the paper. RME wrote the paper, participated in the practical part and in the design of the paper, and revised the paper. All authors read and approved the final manuscript.

\section{Ethics approval and consent to participate}

The aim and procedures of the study were explained to every participant and an informed consent was obtained before being enrolled in the study. The study was approved by the ethical committee of Department of Physical Therapy for Neuromuscular Disorders and its Surgery, Faculty of Physical

Therapy, Cairo University. (NO: P.T.REC/012/001594.). (4th/4/2017(.

\section{Consent for publication}

Not applicable.

\section{Competing interests}

The authors declare that we have no competing interests (financial and nonfinancial). We declare that the research was conducted in the absence of any commercial relationships that could be constructed as a potential conflict of interest.

\section{Publisher's Note}

Springer Nature remains neutral with regard to jurisdictional claims in published maps and institutional affiliations.

\section{Author details}

${ }^{1}$ Physical Therapy of Neuromuscular Disorders and Its Surgery, Faculty of physical therapy, Cairo University, Giza, Egypt. ${ }^{2}$ Department of Neurology, Faculty of medicine, Cairo University, Giza, Egypt.

Received: 14 November 2018 Accepted: 23 May 2019

Published online: 07 June 2019

\section{References}

1. Awad A, Shaker H, Shendy W. Effect of shoulder girdle strengthening on trunk alignment in patients with stroke. Physiothera. 2015;101:1378-9.

2. Hillis A, Kleinman J, Newhart M, Heidler-Gary J, Gottesman R, Barker P, et al. Restoring cerebral blood flow reveals neural regions critical for naming. J Neurosci. 2006;26(31):8069-73.

3. Hillis AE. Stages and mechanisms of recovery from aphasia. Jpn J Neuropsych. 2005;21(1):35-43.

4. Nakayma $H$, Jørgensen $H$, Raaschou $H$, Olsen $T$. Compensation in recovery of upper extremity function after stroke: the Copenhagen stroke study. Arch Phys Med Rehabil. 1994;75(8):852-7.

5. Hardwick D, Lang C. Scapular and humeral movement patterns of people with stroke during range-of-motion exercises. J NeurolPhysiTher. 2011;35(1): $18-25$.

6. Ambegaonkar JP, Mettinger LM, Caswell SV, Burtt A, Cortes N. Relationships between core endurance, hip strength, and balance in collegiate female athletes. Int J Sports Phys Ther. 2014;9(5):604-16.

7. Kibler W, Press J, Sciascia A. The role of core stability in athletic function. Sports Med. 2006;36(3):189-98.

8. Dickstein R, Shefi S, Marcovitz E, Villa Y. Anticipatory postural adjustment in selected trunk muscles in post stroke hemiparetic patients. Arch Phys Med Rehabil. 2004;85(2):261-7.

9. Ryerson S, Byl N, Brown D, Wong R, Hidler J. Altered trunk position sense and its relation to balance functions in people post-stroke. $J$ NeurolPhysiTher. 2008:32(1):14-20.

10. Durall C, Udermann B, Johansen D, Gibson B, Reineke D, Reuteman P. The effects of preseason trunk muscle training on low-back pain occurrence in women collegiate gymnasts. JStren Cond Res. 2009;23(1):86-92. 
11. Cabanas-Valdés R, Bagur-Calafat C, Girabent-Farrés M, Caballero-Gómez F, Hernández-Valiño M, UrrútiaCuchí G. The effect of additional core stability exercises on improving dynamic sitting balance and trunk control for subacute stroke patients: a randomized controlled trial. ClinRehabil. 2016; 30(10):1024-33.

12. Kibler WB, McMullen J. Rehabilitation of scapular dyskinesis. In: Brotzman SB, Wilk KE, editors. Clin orthop rehabil. 2nd ed. St Louis (MO): Mosby; 2003. p. 244-50.

13. Yu S, Park S. The effects of core stability strength exercise on muscle activity and trunk impairment scale in stroke patients. J ExercRehabil. 2013;9(3):362-7.

14. Verheyden G, Vereeck L, Truijen S, Troch M, Herregodts I, Lafosse C, et al. Trunk performance after stroke and the relationship with balance, gait and functional ability. ClinRehabil. 2006;20(5):451-8.

15. Karatas M, C Cetin N, Bayramoglu M, Dilek A. Trunk muscle strength in relation to balance and functional disability in unihemispheric stroke patients. Am J Phys Med Rehabil. 2004;83(2):81-7.

16. Verheyden G, Nieuwboer A, Wit LD, Feys H, Schuback B, Baert I, et al. Trunk performance after stroke: an eye catching predictor of functional outcome. J Neurol Neurosurg Psychiatry. 2006;78(7):694-8.

17. Cabanas-Valdes R, Cuchi GU, Bagur-Calafat C. Trunk training exercises approaches for improving trunk performance and functional sitting balance in patients with stroke: a systematic review. NeuroRehabil J. 2013;33(4):575-92.

18. Neckel ND, Blonien N, Nichols D, Hidler J. Abnormal joint torque patterns exhibited by chronic stroke subjects while walking with a prescribed physiological gait pattern. JNeuroengRehabil. 2008;5(1):5-9.

19. Hsieh C-L, Sheu C-F, Hsueh I-P, Wang C-H. Trunk control as an early predictor of comprehensive activities of daily living function in stroke patients. Stroke. 2002;33(11):2626-30.

20. Cabanas-Valdés R, Urrútia G, Bagur-Calafat C, Caballero-Gómez FM, GermánRomero A, Girabent-Farrés M. Validation of the Spanish version of the trunk impairment scale version 2.0 (TIS 2.0) to assess dynamic sitting balance and coordination in post-stroke adult patients. Top in Stroke Rehabil. 2016;23(4): 225-32.

21. Kim TJ, Seo KM, Kim DK, Kang SH. The Relationship Between Initial Trunk Performances and Functional Prognosis in Patients With Stroke. Ann Rehabil Med. 2015;39(1):66-73

22. Teasell RW, Foley NC, Bhogal SK, Speechley MR. An evidence-based review of stroke rehabilitation. Tops in Stroke Rehabil. 2003;10(1):29-58.

23. Korkmaz NC, Akman TC, Oren GK, Bir LS. Trunk control: the essence for upper limb functionality in patients with multiple sclerosis. MultSclerRelatDisord. 2018:24:101-6.

24. Owolabi M, Akarolo-Anthony S, Akinyemi R, Arnett D, Gebregziabher M, Jenkins $C$, et al. The burden of stroke in Africa: a glance at the present and a glimpse into the future: review article. Cardiovas J Afric. 2015;26(2)::27-38.

25. Bohannon RW, Smith MB. Interrater reliability of a modified Ashworth scale of muscle spasticity. Phys Ther. 1987;67(2):206-7.

26. Velozo CA, Woodbury ML. JSP: translating measurement findings into rehabilitation practice: an example using Fugl-Meyer assessment-upper extremity with patients following stroke. JRehabil Res Develop. 2011;48(10):3.

27. Edwards DF, Lang CE, Wagner JM, Birkenmeier R, Dromerick AW. An evaluation of the Wolf motor function test in motor trials early after stroke. Arch Phys Med Rehabil. 2012;93(4):660-8.

28. Verheyden G, Nieuwboer A, Mertin J, Preger R, Kiekens C, Weerdt WD. The trunk impairment scale: a new tool to measure motor impairment of the trunk after stroke. ClinRehabil. 2004;18(3):326-34.

29. Khamwong P, Nosaka K, Pirunsan U, Paungmali A. Reliability of muscle function and sensory perception measurements of the wrist extensors. PhysiotherTheo Practi. 2010;26(6):408-15.

30. Ylinen J. Stretching therapy for sport and manual therapies. Churchill Livingstone, Elsevier, 2007 and 2008. Medirehabook INC. 2 nd revised ed. 2013.

31. Kisner C, Colby LA. The spine: traction procedures therapeutic exercise: foundations and techniques. 3rd ed. Philadelphia: F.A. Davis Co; 1996. p. 575-91.

32. Karthikbabu S, Nayak A, Vijayakumar K, Misri Z, Suresh B, Ganesan S, et al. Comparison of physio ball and plinth trunk exercises regimens on trunk control and functional balance in patients with acute stroke: a pilot randomized controlled trial. ClinRehabil. 2011;25(8):709-19.

33. Chung E-J, Kim J-H, Lee B-H. The effects of core stabilization exercise on dynamic balance and gait function in stroke patients. J PhysiThera Sci. 2013; 25(7):803-6.
34. Gallo R. Moctezumas revenge, Or, Sarduyln Princeton. The Princeton University Library Chronicle. 2012;73(3):432.

35. Fisiolab P. Core Stability. Sports Health. 2013;5(6):514-22.

36. Sun X, Gao Q, Dou H, Tang S. Which is better in the rehabilitation of stroke patients, core stability exercises or conventional exercises? J Physi Thera Sci. 2016;28(4):1131-3.

37. Kang D-W. Neuronal metabolic changes in the cortical region after subcortical infarction: a proton MR spectroscopy study. J NeurolNeurosurg Psychiatry. 2000;69(2):222-7.

38. Michaelsen SM, Dannenbaum R, Levin MF. Task-specific training with trunk restraint on arm recovery in stroke. Stroke. 2006:37(1):186-92.

39. Freeman J, Fox E, Gear M, Hough A. Pilates based core stability training in ambulant individuals with multiple sclerosis: protocol for a multicentrerandomised controlled trial. BMC Neurol. 2012;12(1):1.

40. McGill S. Low Back disorders: evidence based prevention and rehabilitation. J Can Chiropr Assoc. 2007;51(2):124.

41. Jamison ST, Mcneilan RJ, Young GS, Givens DL, Best TM, Chaudhari AMW. Randomized controlled trial of the effects of a trunk stabilization program on trunk control and knee loading. Med Sci SportsExerc. 2012;44(10):1924-34.

42. Lust KR, Sandrey MA, Bulger SM, Wilder N. The effects of 6-week training programs on throwing accuracy, proprioception, and core endurance in baseball. J Sport Rehabil. 2009:18(3):407-26.

43. Ellis MD, Sukal T, Demott T, Dewald JPA. Augmenting clinical evaluation of hemiparetic arm movement with a laboratory-based quantitative measurement of kinematics as a function of limb loading. Neurorehabil Neural Repair. 2007:22(4):321-9.

44. Michaelsen SM, Luta A, Roby-BramiAgnès LMF. Effect of trunk restraint on the recovery of reaching movements in hemiparetic patients. Stroke. 2001; 32(8):1875-83.

45. Wee SK, Hughes A-M, Warner MB, Brown S, Cranny A, Mazomenos EB, et al. Effect of trunk support on upper extremity function in people with chronic stroke and people who are healthy. Phys Ther. 2015;95(8):1163-71.

46. Miyake Y, Kobayashi R, Kelepecz D, Nakajima M. Core exercises elevate trunk stability to facilitate skilled motor behavior of the upper extremities. J Bodywork MoveTherapie. 2013:17(2):259-65.

47. Woodbury ML, Howland DR, Mcguirk TE, Davis SB, Senesac CR, Kautz S, et al. Effects of trunk restraint combined with intensive task practice on poststroke upper extremity reach and function: a pilot study. Neurorehabil Neural Rep. 2008;23(1):78-91.

48. Jijimol G, Fayaz RK, Vijesh PV. Correlation of trunk impairment with balance in patients with chronic stroke. NeuroRehabil J. 2013;32(2):323-5.

49. Verheyden G, Nieuwboer A, Feys H, Thijs V, Vaes K, Weerdt WD. Discriminant ability of the trunk impairment scale: a comparison between stroke patients and healthy individuals. DisabilRehabil. 2005:27(17):1023-8.

50. Saeys W, Vereeck L, Truijen S, Lafosse C, Wuyts FP, Heyning PVD. Randomized controlled trial of truncal exercises early after stroke to improve balance and mobility. Neurorehabil Neural Rep. 2011;26(3):231-8.

51. Verheyden G, Vereeck L, Truijen S, Troch M, Lafosse C, Saeys W, et al. Additional exercises improve trunk performance after stroke: a pilot randomized controlled trial. Neurorehabil Neural Rep. 2008;23(3):281-6.

52. Wee SK, Hughes A-M, Warner M, Burridge JH. Trunk restraint to promote upper extremity recovery in stroke patients. Neurorehabil Neural Rep. 2014; 28(7):660-77.

53. Kumaresan A, Mahiba JA. Effect of core muscle exercises in improving reaching activities in participants with hemiplegia. Int J Pharma Bio sci. 2016;7(3):1096-104. 